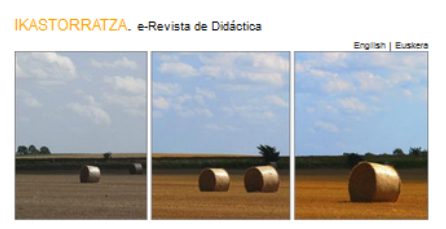

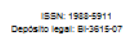

Inicio, Sobre nosotros, Publicacionesı, Participa

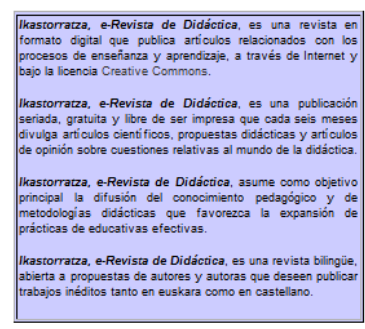

\section{IKASTORRATZA. Didaktikarako e-aldizkaria}

\author{
IKASTORRATZA. e-journal on Didactics
}

ISSN: 1988-5911 (Online) Journal homepage: http://www.ehu.eus/ikastorratza/

\title{
A proposal to teach implicature to intermediate students of English
}

\author{
IKASTORRATZA. e-Revista de \\ Didáctica
}

Juan Carlos Araujo Portugal

jcaraujo@educa.jcyl.es

To cite this article:

Araujo, J.C. (2020). A proposal to teach implicature to intermediate students of English. IKASTORRATZA. e-Revista de Didáctica, 25, 96-132. DOI: 10.37261/25_alea/4

To link to this article:

https://doi.org/10.37261/25_alea/4

Published online: 31 october 2020 


\title{
A proposal to teach implicature to intermediate students of English
}

\section{Propuesta didáctica para enseñar el concepto de implicatura a alumnos de inglés de nivel intermedio}

\author{
Juan Carlos Araujo Portugal \\ Escuela Oficial de Idiomas de Burgos \\ jcaraujo@educa.jcyl.es
}

\begin{abstract}
Teaching pragmatics in language learning is growing more and more relevant in order to achieve the goal that the speakers of a language can communicate effectively with both native and non-native speakers. As a result, misunderstandings when communicating will be avoided. Within pragmatics, implicature is one of the most problematic aspects for students to grasp. Besides, not being able to handle it correctly may interfere or even hinder communication. Therefore, teaching implicature effectively becomes a must for twenty-first century teachers. This means that their goal has to be to equip their students with the necessary skills they will need to manage successfully in a globalised world where English is used as a lingua franca. This paper begins by revising the main concepts about pragmatic competence, together with the most common and effective ways to teach pragmatics. Then, some possible ways to assess the acquisition of pragmatic competence, as well as a proposal to teach implicature to intermediate students of English are presented in this paper. The proposal takes as a reference the different stages, activities, kind of input, materials and ways to teach and assess implicature that have proven effective in previous research studies into this issue. The different parts of this proposal are described, as well as the materials to be used with it. They are mainly authentic input, as well as examples of the most habitual types of activities employed for this purpose. Finally, the results which are expected to be achieved through this proposal are outlined.
\end{abstract}

Keywords: Implicature, materials, pragmatic competence, pragmatics, teaching proposal 


\section{Resumen}

En el aprendizaje de idiomas la enseñanza de la pragmática adquiere una mayor relevancia a la hora de lograr que los hablantes de una lengua sean capaces de comunicarse de forma efectiva tanto con hablantes nativos como no nativos, para de ese modo evitar equívocos o malos entendidos en la comunicación. Dentro de la pragmática, la implicatura es uno de los aspectos que a los alumnos les resultan más difíciles de asimilar, y el hecho de no dominarlo puede dificultar, e incluso impedir, la comunicación. Es por ello que enseñar este aspecto de forma efectiva se convierte en una auténtica necesidad para los docentes del siglo XXI, para que puedan dotar a sus alumnos de las destrezas necesarias para desenvolverse con éxito en un mundo globalizado donde el inglés se emplea como lingua franca. Tras llevar a cabo un repaso de los principales conceptos relacionados con la competencia pragmática, junto con las formas más habituales y efectivas de su enseñanza, así como posibles modos de evaluar la adquisición de la competencia pragmática, este artículo incluye una propuesta didáctica para la enseñanza de la implicatura que está pensada para estudiantes de inglés de nivel intermedio. La propuesta didáctica toma como referencia las distintas partes, las actividades, el tipo de input, los materiales y los métodos para la enseñanza y la evaluación de la implicatura que se han demostrado efectivos en anteriores investigaciones en relación a este tema. El artículo describe las diferentes partes de la propuesta, así como los materiales que se sugiere que se empleen en ellas, que primordialmente se tratan de materiales auténticos, al tiempo que se incluyen ejemplos de los tipos de actividades más frecuentes que se usan para este fin. Por último, se exponen los resultados que se esperan conseguir por medio de esta propuesta.

Palabras clave: Competencia pragmática, implicatura, materiales, pragmática, propuesta didáctica 


\section{Introduction}

Learning a language implies being able to use it accurately and fluently. This involves knowing the grammatical rules and vocabulary needed to convey a message without making mistakes, and being able to communicate with other people effectively. However, sometimes even very proficient students may have to deal with misunderstandings. The reason for this is that they do not behave in the expected way in a particular situation, or do not observe the rules which are supposed to be operative in a specific context.

This has to do with pragmatics which, as authors such as Bouton (1994), Kasper (2001), Takahashi (2001), Tateyama (2001), Yoshimi (2001), etc. point out, is not usually taught in foreign language courses, or is not included in most coursebooks. Even if it is, textbooks do not usually reflect the authentic use of the language. As will be seen in this paper, this calls for the teaching of pragmatics, in the same way as the grammar, vocabulary, phonology, morphology, etc. of a language are taught.

This paper includes a teaching proposal on an important aspect of pragmatics, namely, conversational implicature, which can lead to misunderstandings if students do not know how it works, or have not had any practice in it. The main goal of the teaching proposal is to raise students' awareness on this concept, and in a more modest way, to give them the necessary training both to understand this phenomenon and also to use it appropriately.

Besides, and once they are familiar with this aspect, students are expected to start registering examples of conversational implicature as they encounter them in any media while using the language. For example, when watching a film or TV programme, on videos from YouTube, when reading novels, articles, essays, journals, etc., or simply while having a conversation with a native speaker.

This paper will first revise the most relevant literature on pragmatics, beginning with the concept of implicature, and most specifically conversational implicature. Then, the usefulness of instruction of pragmatics in general, and of conversational implicature in particular, will be examined. Next, the main methods and instruments to assess pragmatic competence, which can also be used by instructors and textbook authors to develop teaching materials, will be described. Finally, the most common ways employed to teach pragmatics will be dealt with. After the literature review, the 
procedure for the teaching proposal will be presented following the guidelines suggested by Ishihara (2010a). Then, the teaching proposal as such will be explained in a detailed way.

\section{Literature review}

This section will focus on some relevant aspects regarding pragmatics that will help understand the teaching proposal better. First of all, it will begin by paying attention to pragmatic competence. Then, the concept of implicature, and more specifically conversational implicature, will be defined. Apart from this, this section will focus on the effectiveness of teaching pragmatics, on methods and instruments to assess pragmatic knowledge and develop pragmatic competence, as well as on the most common ways to teach pragmatics.

\subsection{Pragmatic competence}

Pragmatic competence may be defined as the ability "to go beyond the literal meaning of what is said or written, in order to interpret the intended meaning, assumption, purposes and goals, and the kind of actions that are being performed” (Cohen, 2010, p. 8).

Interpreting what speakers mean from a pragmatic point of view can be challenging for both native and non-native speakers. The reason for this is that people sometimes express what they intend to say in an indirect way, and the recipients are the ones who have to interpret the intention behind the message. This interpretation often requires good knowledge of both social and cultural rules or norms (Cohen, 2010).

Authors such as Leech (1983) and Thomas (1983) distinguish two further competences within pragmatic competence, namely, pragmalinguistics and sociopragmatics. Pragmalinguistics "refers to knowledge of the range of options available for performing various pragmatic actions, and sociopragmatics refers to the knowledge of how to select an appropriate choice given a particular goal in a particular setting” (O’Keeffe, Clancy, \& Adolphs, 2011, p. 138).

Pragmatics includes aspects such as the degree of politeness used, speech acts (e.g. greetings, thanking, requests, complimenting, apologising, complaining, etc.), 
"conversational style, humour, sarcasm, teasing, cursing, discourse markers, conversational implicature, and deixis” (Cohen, 2016, p. 523).

\subsection{Implicature}

Davis (2016) defines implicature as "meaning one thing by saying something else" (p. 1). Similarly, Cignetti and Di Giuseppi (2015) state that when we communicate, apart from words, we may use other linguistic devices to convey what we actually mean. Two types of implicature - semantic and conversational implicature - may be differentiated. The former denotes the actual meaning of the words used in a particular sentence or message, whereas the latter can only be understood within the specific context where it is expressed. As Davis (2016) states, conversational implicature depends on the context, whereas semantic implicature refers to the actual meaning of the sentence. Peccei (1999) adds that successful implicature requires that both the sender and recipient of a message share a good deal of knowledge. Goded Rambaud (2012) seems to agree with this idea. This is why Peccei (1999) maintains that implicatures depend on the context, on the one hand, and also on the knowledge that both the speaker and the hearer share on the other.

As Davis (2016) also points out, conversational implicature is not an unusual phenomenon. As a matter of fact, it is quite common in everyday language, whether it is in written or oral form. Besides, it cannot be identified with a specific language, as it is a habitual occurrence in any language. According to this author, its use is a characteristic feature that distinguishes human language from any other types of communication.

Besides, Davis (2016) highlights that one of the reasons for using implicature might be that it becomes a typical habit of each speaker, or that it is something spontaneous. For his part, Levinson (2000) argues that people tend to speak or write at a slower rate than they think or understand messages, which may result in a kind of "bottleneck in the communication process”, as Davis (2016, p. 15) puts it. One way of avoiding this potential problem is to convey more ideas through a sentence than what it actually expresses, e.g. by resorting to implicature. Blome- Tillmann (2013) also agrees with this, and considers that both exaggeration and irony are good examples of it. 
Moreover, Davis (2016) also suggests that another reason to use implicature may be that it is an effective way to avoid lying to people. This can be achieved by misleading them and deceiving them into believing something that is not true or completely true, or simply by not revealing all the information they know about a particular issue. He also points out that implicature may serve the purpose of maintaining good social relationships with other people "by being polite, tactful, respectful, modest, sympathetic and deferential” (Davis, 2016, p. 16).

Conversational implicature takes Grice’s (1975) theory as a basis. According to him, in any conversation there must be a basic principle operative, namely, the cooperative principle, which implies that, when communicating, the participants in a conversation “will co-operate with each other when making their contribution” (Peccei, 1999, p. 27). As Peccei indicates, this main principle can be divided into four maxims which ensure the effectiveness of the cooperative principle. These maxims may be described as follows (Goded Rambaud, 2012):

a) Quality. You should try to contribute with something that you believe to be true.

b) Quantity. You should try to make your contribution as informative as necessary for effective communicative purposes. This implies that you should avoid adding unnecessary information.

c) Relevance. What you say must be relevant to the conversation that is taking place.

d) Manner. You should avoid ambiguity and obscurity so that your contribution is not difficult to understand and to avoid misleading information or messages.

However, these maxims are not always respected in conversations. According to Blome-Tillmann (2013), Grice 's maxims should be seen as criteria or guidelines that help us reconstruct and interpret conversational implicatures, rather than as detailed explanations of the cognitive processes that undergo conversations. Leech (1983) argued that the way these maxims operate depends on each community. Consequently, this may result in misunderstanding some implicatures which are perfectly obvious to a specific society, but not to another one. This would make it necessary to instruct students as regards the implicatures operative in different contexts in a specific target language, as their interpretations may be different from those of the native speakers of this language (Bouton, 1994; Kubota, 1995). 
Apart from Grice's maxims, other theories have been put forward. For example, Sperber and Wilson's (2004) Relevance Theory, which has to do with raising expectations of relevance as regards what a speaker means with their utterances. According to Sperber and Wilson (2004), "the search for relevance is a basic feature of human cognition, which communicators may exploit” (p. 608). For an input to be relevant, it is necessary that it relates to background information available to the hearer, so that they reach conclusions that are important to them. These authors also point out that there are many inputs around us that may be relevant to us. However, we cannot pay attention to all of them. From the ones existing at a given time, we only focus on the one that we consider most relevant.

Research theory also claims that having equal inputs, one tends to focus on those that produce more positive cognitive effects and require less processing effort. As Sperber and Wilson (2004) highlight, even though there may be more expectations, the hearer will not usually go any further than the first interpretation that satisfies their expectation of relevance. This has implications for the speaker as well, because they should formulate their utterance in the easiest possible way, so that it is quite straightforward for the hearer to reach their first interpretation, ignoring the other alternatives.

Grice resorted to his cooperative principle and maxims to explain implicatures. In contrast, Relevance Theory tries to go further, and explain other pragmatic aspects of language use, such as loose uses of language, which cannot be really explained by Grice (Sperber \& Wilson, 2004). For these authors, just like metaphors and hyperboles, they are alternative ways to attain maximum relevance. In order to do so, they may be interpreted literally or figuratively.

\subsection{Effectiveness of teaching pragmatics}

Several authors such as Bouton (1994), Kasper (2001), Takahashi (2001), Tateyama (2001), Yoshimi (2001), etc. have frequently highlighted the benefits for students of explicit instruction of pragmatics, both in second language (SL) and foreign language (FL) environments. According to Ishihara and Cohen (2010), it takes "over 10 years to acquire native-like pragmatic ability, even in a second-language setting” (p. 201), but this process can be hastened by teaching it effectively (Timpe-Laughlin, 2016). This is 
due to the fact that pragmatic competence does not develop at the same rate as grammatical competence (O’Keeffe et al., 2011). Therefore, in the case of FL learners, it seems to be even more relevant, as students are less likely to be exposed to the target language, and will also have fewer chances to use the language in authentic contexts (Cignetti \& Di Giuseppi, 2015). Fukuya and Martínez-Flor (2008) consider that instruction is particularly useful in the case of adult students, regardless of their level, both in SL and FL environments. Besides, Cohen (2016) adds that acquiring pragmatic competence on their own may be very difficult or demanding for students.

In the context of pragmatics, instruction does not necessarily imply teaching new subject-matter. It involves making students aware of how it works while referring them to what they already know about the target language, and to their pragmatic knowledge of L2. Thus, they will be able to work out what speakers intend with their messages rather than interpret them literally.

Related to this, Kecskes (2014) states that people's prior knowledge of recurring contexts that the speaker includes in their messages plays an important role when it comes to constructing and understanding meaning. According to this author, what the hearer understands is not always what the speaker intended, as both of them may have different cognitive contexts and prior experiences. This is even more relevant in the case of intercultural communication, where interlocutors have different mother tongues and come from different cultures, which may not have many things in common. In line with this, Kecskes (2014) draws attention to formulaic language, which is characteristic of “native-like language use” (p. 105).

As this author also highlights, in intercultural communication non-native speakers have limited common knowledge and experiences, which poses a problem as regards the use of formulaic expressions. This kind of language has fixed meanings that cannot be easily deciphered from the context. Non-native speakers tend to avoid using these expressions fearing that their addressees may not be able to understand them correctly. As non-native speakers come from different backgrounds and cultures, they are likely to organise background knowledge in a different fashion. The only thing non-native speakers are certain to have in common is the target language (Kecskes, 2014). As this author also claims, non-native speakers learn these expressions as part of their learning process without fully understanding the "socio-cultural load that they carry" (p. 117). As a result, non-native speakers tend to favour the literal rather than the figurative 
meaning of language use, which in turn may lead to misunderstandings when they encounter these expressions. Kecskes (2014) also remarks the importance of context in order to interpret an utterance properly. As he points out, recurring contexts will help comprehend the intended meaning conveyed by a formulaic expression.

Some research studies, such as Jiang (2000), Kecskes and Cuenca (2005), and Kroll and Stewart (1994), prove that in the first stages of foreign language learning, when a student comes across a new word in the target language, they tend to resort to their mother tongue to find the closest equivalent. However, the concept that the word or phrase in the target language represents may be different from that of L1, as concepts are normally characteristic of each culture. As learners become more proficient in L2, they are usually less dependent on these associations with their mother tongue. The reason for this is that they start referring to the target language to grasp the intended meaning of the new L2 words or expressions they encounter, as they have already acquired some socio-cultural knowledge and experience in the target language. Socialising in L2 also helps learners acquiring the meaning of these expressions used figuratively rather than literally (Kecskes, 2014).

Cignetti and Di Giuseppi (2015) provide evidence about the literal interpretation of the messages by the students in their research study. Most of their misinterpretations were due to this, as they failed to infer the implied meaning of the messages that they were presented with, and ignored all the contextual information that could help them understand this implied meaning. Instead, learners could resort to the existing pragmatic knowledge of their mother language, but they quite often ignored it. This calls for instruction of pragmatics as an effective way to develop pragmatic competence in the target language (Rose \& Kasper, 2001).

Cignetti and Di Giuseppi (2015) also point out that in the case of interlanguage pragmatics, research studies have focused on "production rather than judgement and perception” (p. 4). By focusing on the latter, it would be possible to see whether there are any differences in the way native and non-native speakers of the target language interpret a message, which otherwise would be difficult to be examined (BardoviHarlig, 2001). 
Consequently, input becomes pivotal when it comes to teaching pragmatics, even though simple exposure to it does not seem to be enough (Cohen, 2016). The idea of teaching pragmatics to students advocates Schimdt's (1990) Noticing Hypothesis, according to which contents will only be learned by students, i.e. become intake, if learners notice them consciously (Rose \& Kasper, 2001).

As Schmidt (1995) puts it, noticing means "conscious registration of the occurrence of some event”, whereas understanding “implies the recognition of some general principle, rule or pattern” (p. 29). Clennell (1999) and Tomlinson (1994) highlight the paramount role of discovery in the process of noticing in order to lead to pragmatic awareness (Bardovi-Harlig, Mossman \& Su, 2017). More specifically, Clennell states how "learners need to feel that they have arrived at their discoveries through their own efforts” (p. 87).

Cignetti and Di Giuseppi (2015) acknowledge that pragmatic input is one of the factors that may have an influence on the development of pragmatic competence when learning a foreign language. However, these authors, as well as others such as Bardovi-Harlig (2001) and Hilliard (2017), etc., point out that most textbooks are not a trustworthy source of pragmatic input. The reason for this is that this input is not always realistic or contextualised, or that some pragmatic features are presented in a superficial way. Instead, videos, films and TV programmes are often used as input, as they are considered to present a more realistic use of the target language in authentic contexts (Alcón Soler, 2005). Hilliard (2017) concludes that only presenting students with the input material that comes in textbooks will have as a result that they will not be able to develop their pragmatic competence enough so as to engage in communication effectively.

On the other hand, Timpe-Laughlin (2016) argues that both explicit instruction and the comparison of specific phenomena between students' mother tongue and the target language can help learners develop pragmatic competence and understand how pragmatics works in the foreign language. Eslami-Rasekh (2005) and Limberg (2015) also agree with this idea. More specifically, the latter considers that class discussions that compare both the languages and the cultures are particularly effective in this sense. 
Both authors propose activities where students compare different speech acts in both the target language and their mother tongue. Another way to raise students' pragmatic awareness is to ask them to read texts or watch videos which include explicit explanations of specific speech acts in the foreign language.

Bardovi-Harlig and Mahan-Taylor (2003) propose this three-step procedure in order to teach pragmatics to foreign language learners:

a) Using authentic language input.

b) This input must then be interpreted, and if possible produced.

c) Beginning to teach pragmatics at lower levels.

These authors see the language class as a safe environment for students in order to develop and acquire pragmatic competence. In this context, teachers can provide their students with the feedback they need so as to understand how pragmatics in the target language works. Martínez-Flor and Usó-Juan (2010) highlight that, apart from input, both output opportunities and feedback on students' performance are essential. In this sense, it is worth mentioning that Fukuya and Martínez-Flor (2008) highlight that the perceived benefits of explicit instruction of pragmatics may differ. This will depend on how demanding the tasks or activities devised to assess this effectiveness are. This is why they advised using different kinds of tasks or activities to ascertain the effectiveness of instruction as regards the development of pragmatic competence in the target language.

\subsection{Methods and instruments to assess pragmatic knowledge and develop pragmatic competence}

There are different ways to present pragmatic input, measure pragmatic competence, and to collect data on pragmatics. One of the reasons why coursebooks may not be regarded as a reliable source of input is that their dialogues and conversations are based on the authors' intuition rather than on natural or authentic use (Ishihara \& Cohen, 2010). However, as Judd (1999) and Kasper (1999) point out, this intuition might not always be accurate, even in the case of native speakers. Although some later authors such as Farashaiyan, Tan and Shahragard (2018), Ghasemi and Pasand (2018), Karlsson (2019), Tran and Yeh (2020), and Wang (2019) have reported a slight improvement in 
this sense, the input provided by textbooks is still considered insufficient, inadequate, oversimplified or not really authentic.

As said above, a number of instruments and methods to assess pragmatic competence and acquisition are quite common. For example, Cignetti and Di Giuseppe (2015) used a written multiple choice questionnaire as pre- and post-test once their treatment had been implemented. Both tests consisted of several items that contained "brief descriptions of a situation with a dialogue. Twelve contained an implicature and the remaining were distracters" (p. 7). In this case, the students had to choose the most likely response to each conversation. Conversely, in other studies, e.g. Bouton (1994) and Kubota (1995), the options provided focused on interpreting the meaning of the responses. According to Martínez-Flor and Usó-Juan (2011), multiple choice questionnaires are particularly suitable methods "to measure recognition and interpretation of utterances” (p. 50).

However, one of the most common methods used to assess pragmatic competence are discourse completion tasks (DCTs), "which contain prompts to elicit different pragmatic responses” (Hilliard, 2017). But apart from this, they may also be employed as class activities aiming at developing learners’ pragmatic knowledge (Eslami-Rasekh, 2005). Typically, DCTs include a "written description of a situation followed by a short dialogue with an empty gap that has to be completed by the learner” (Martínez-Flor \& Usó-Juan, 2011). Two different kinds of DCTs may be distinguished, namely singleturn DCTs, where students are expected to provide a single response, and multiple DCTs, which may lead to more extended dialogues or conversations. McLean (2005) proposes another type of DCTs called student-generated DCTs, where the students are the ones who develop the scenarios on which the DCTs are based.

Another typical way of assessment is role plays, where students are presented with a scenario or situation and are expected to carry out the situation analysing what they would say in this context. This implies paying attention to what the participants in the conversation say, so as to provide a response that sounds appropriate to the context (Ishihara \& Cohen, 2010). Kasper and Dahl (1991) state that role plays favour interaction and spontaneity and are, therefore, more likely to reflect more authentic discourse than DCTs.

As these authors point out, both DCTs and role plays allow researchers to collect a fairly large amount of data in an easy and quick way. Besides, in both cases the 
interactional data "are obtained under controlled conditions, since the researcher can determine the setting of the interaction and control the variables intervening in it" (Martínez-Flor \& Usó-Juan, 2011, p. 50). Félix-Brasdefer (2010) also agrees with these authors. However, these methods, and DCTs in particular, as they are in written form, have been somehow disapproved of by many researchers because they do not reflect actual speech faithfully.

Another type of activity that Hilliard (2017) suggests is the analysis and correction of pragmatic errors, as this seems to increase students' pragmatic awareness and competence. The idea behind this kind of activity is that it is a sort of training that will eventually allow students to analyse and "repair their own conversations and experiences” (p. 10) if they are not accurate from a pragmatic point of view.

\subsection{Typical ways of teaching pragmatics}

As regards the most common ways to teach pragmatics and the materials employed to do so, they seem to be quite similar, and most authors present them in the research studies that they carry out. As far as the most habitual types of instruction are concerned, explicit and implicit instruction seem to be the most widely used. The main difference between them is that "explicit instruction involves directing learners' attention towards the forms with the aim of discussing those forms". However, implicit instruction “aims to attract learners' attention while avoiding any type of metalinguistic explanation and minimising the interruption of the communicative situation” (MartínezFlor \& Beltrán-Palanques, 2013, p. 43).

Focusing on specific examples of some research studies, in the case of Cignetti and Di Giuseppe (2015), their treatment was carried out in five one-hour sessions over a threeweek period. As regards the materials they used, video excerpts and photocopies were the main ones. They served as the basis for discussions as a whole group, which were used to present the different types of implicatures, and activated the development of generalisations about the functioning of implicatures. For her part, Ishihara (2010b) used a film to show how speakers convey their messages and how these can be interpreted by their addressees. Alcón Soler (2005) also agrees with the idea of using films as pragmatic awareness-raising input in the target language. 
Specifically referring to Cignetti and Di Giuseppe's (2015) first session, it was used as an introduction to conversational implicature as a way to communicate in an indirect way. However, Ishihara (2010b) used the first session to assess students' initial level of pragmatic competence and awareness, and also to encourage and motivate them to learn about pragmatics.

Bardovi-Harlig, M o ssman and Vellenga (2015) devised lessons that presented students with input and which also included output activities or tasks which enabled learners to produce appropriate pragmatic expressions and output. Therefore, their lessons consisted of the following parts or stages:

a) A warm-up activity.

b) Focused-noticing activities.

c) Explicit instruction.

d) Production activities.

As part of the noticing stage, the students were asked to identify any pragmatic features that were included in the texts they heard or read. As for the explicit instruction, the main focus was on the form of the expressions that were characteristic of the speech act under study. Similarly, Bardovi-Harlig et al. (2017) also followed the same procedure a warm-up activity, a noticing stage, explicit instruction, and oral production practice.

Apart from films, online corpora may be used as sources of authentic language samples to be presented to students as language input, because "they reflect the way that language is actually used” (Ishihara \& Cohen, 2010, p. 175). Bardovi-Harlig et al. (2015) point out that corpora can provide two main types of information, namely, expression frequency and expression context. These authors also suggest that students may be taught and trained to use corpora themselves in order to find out the frequency of use of the expressions that they learn. According to Bardovi-Harlig et al. (2015), corpora can be used to extract content that is employed to develop activities whose main aim is noticing. 


\section{Procedure}

The teaching proposal presented in this paper has been designed to be carried out with intermediate students of English who are supposed to have reached B1 level of the Common European Framework of Reference for Languages (CEFRL). They are either adults or young adults who attend an Escuela Oficial de Idiomas twice a week. Each day they come to class they have a two-hour session, and there is an extra two-hour session per month, so that they have an average of 4.5-hour instruction per week. The number of attending students may vary from group to group, and it tends to become lower as the academic year progresses as this is not compulsory education. Besides, other commitments such as studies, family, work, etc. quite often make them stop coming to class altogether or for shorter or longer periods of time.

Even though Bardolig-Harlig and Mahan-Taylor (2003) recommend starting to teach pragmatics at low levels of proficiency in the language, most research studies have focused on students who have already acquired an intermediate or advanced level. This is why this specific level has been selected for the teaching proposal.

As for the students' experience with English, most of them are not expected to have spent a fairly long time in an English-speaking country. They mainly learn English as a hobby; to help their children with their homework, especially as many of them are following a bilingual programme based on CLIL methodology; to have better career prospects either in their own country or abroad; for travelling, although not necessarily to English-speaking countries, which means that they mainly want to use English as a lingua franca; for their studies, work, etc.

Many of these students are supposed to be quite autonomous learners, in the sense that they usually watch films and TV series in the original version, or read books in English, either adapted or unabridged. Besides, some of them normally make use of online resources specifically created for English language learners, or the additional resources provided by their textbook which are intended for autonomous work.

The teaching proposal is envisaged to be developed throughout the academic year, which is why it is divided into three main parts (See appendix 1 for the overall structure of the teaching proposal). The first one will be carried out at the beginning of the course, approximately one month after it has begun. In this way, there will be a good atmosphere in the group; the students will have been able to get to know one another so 
as not to feel embarrassed when discussing different issues in public, and will also have become accustomed to the way of working in class. The second part will take place in the middle of the course, and the third one towards the end of the course, before it actually finishes.

As far as the first part is concerned, its main purpose as regards teaching implicature will be to raise the students' awareness of the issue, and will also serve as an initial assessment of the students' knowledge about it. This would, therefore, be similar to what Ishihara (2010b) did in her research study. Besides, and at a very elementary level, it would try to encourage students to think of their own scenarios where implicature is generated, as well as to start registering examples of implicature that they come across during their learning process. Both the mid-course and end-of-course parts will try to establish whether any obvious improvement may be perceived in comparison with students’ initial knowledge about pragmatic competence.

As for the initial part at the beginning of the course, it is expected to be developed over at least three sessions, which amounts to a minimum of 3-hour instruction. As regards the activities for this part, they will be based on what Bardovi-Harlig et al. (2015) propose, namely, warm-up activities, focused-noticing activities, explicit instruction, and production activities. The main aim of the teaching proposal is to focus on judgement and perception, rather than on production, as the former seem to have been neglected when it comes to developing pragmatic competence according to Cignetti and Di Giuseppi (2015). In this way, the students will find it easier to understand what native speakers intend when they use implicature, and thus it will contribute to minimising misunderstandings as much as possible due to the interpretation of the literal meaning of messages. However, even though at a not very ambitious level, the students will also be encouraged to try to carry out some output activities, as they are also necessary for the acquisition and development of pragmatic competence, as Martínez-Flor and Usó-Juan (2010) point out.

As for the warm-up activity, the students will be presented with a short video excerpt in English which contains a clear example of implicature. The idea is that this will lead students to reflect on their own experience with implicature, firstly in their mother tongue and then in the target language, if they have already had any experience of it in the latter. Both Limberg (2015) and Timple-Laughin (2016) consider class discussions 
very useful for the development of pragmatic competence and the correct interpretation of pragmatic phenomena in the foreign language.

However, some students, particularly shyer ones, may feel intimidated by the whole group and do not tend to contribute to group discussions. This is the reason why the discussion will first take place in pairs or in small groups, and then all the opinions will be pooled together during the whole group discussion. In this way, there will be more contributions and the activity will prove more beneficial to all the students.

After the initial warm-up activity, the students will be presented with a few examples of implicature or misinterpretations due to implicature. This, together with the discussion that they may trigger, will correspond to focused-noticing stage. As coursebooks are not very reliable sources of input, and as many authors recommend using videos or films for this purpose, video excerpts from YouTube will be used for these focused-noticing activities. More specifically, the examples that the students will be presented with will mainly be excerpts from TV series. Once again, this activity will be first done in pairs and then as a whole group, to allow all the students to give their opinion and compare it with their partners'.

Even though corpora have proven useful as sources of authentic input, they do not seem to be particularly appropriate in the case of implicature in order to find relevant examples. If this is already fairly difficult in the case of other pragmatic phenomena, it is even more in the case of implicature. This is so unless you know about specific examples in advance, so that the excerpts from corpora may provide more contextualised information, or may be used as the script of an excerpt from a film, TV programme or video.

As for explicit instruction, the concept of implicature and Grice's (1975) maxims will be provided to students by both the teacher and through tutorials from YouTube. This second way will surely prove very convenient for students, as they may refer to them outside class as often as they wish, whenever they want to revise any of the main concepts related to implicature. Following Timple-Laughlin (2016), explicit instruction, together with the comparison of specific pragmatic phenomena in both the students' mother tongue and in the foreign language, will surely prove useful and effective for the development of pragmatic competence in the foreign language. Apart from this, it will also help the students understand how pragmatics works in L2. 
To finish the first part of the teaching proposal, the students will be provided with production activities, or rather recognition exercises. Even though DCTs and role plays are the most common tools to collect data on pragmatic competence and to assess it, they are not regarded as the most suitable methods or instruments in the case of implicature. As Cignetti and Di Giuseppi (2015), as well as Martínez-Flor and Usó-Juan (2011) suggest, multiple choice questionnaires seem more appropriate to ascertain whether students can recognise and interpret utterances accurately.

Therefore, working in pairs or in small groups, the students will be asked to interpret the intended meaning of some written messages or extracts. After a few practice exercises, instead of providing students with the possible meanings of the messages, they will be presented with new scenarios and extracts where students will have to infer what the speaker intended with their answer. This time, the difference will be that they will no longer have help, as they will not be provided with any possible answers. Rather than the teacher devising them, these extracts will be taken or adapted from tasks or activities used by some authors in their research studies, as long as they have proven effective. After going through these questionnaires in pairs or small groups, the answers will be discussed as a whole group.

Finally, and in a really more productive way, in pairs or in small groups, the students will be encouraged to construct their own scenarios and messages in the FL containing implicature for their classmates to infer the implied meaning. In the same way as McLean (2005) suggests student-generated DCTs, this student-generated scenarios and samples seem to be effective, but without trying to be particularly ambitious.

To actually end this first part, the students will be encouraged to start registering any examples of implicature that they encounter from that moment onwards. For example, while they are watching TV programmes, films or videos in English, or reading novels or articles in English, or just having a conversation with a native English speaker. Apart from registering them, the students will be expected to analyse these examples or samples, in order to understand and interpret them accurately.

Once this first part has finished, and approximately on a monthly basis, there will be a one-hour session devoted to the revision and consolidation of the main concepts regarding implicature, and the students will be presented with some new examples containing implicature to try to work out their implied meaning. Besides, and once again working in pairs or in small groups, the students will comment on some of the 
examples containing an implicature that they have registered since the previous session. They are expected to check to what extent they agree that the examples discussed contain an implicature. After a few minutes, they will present to the whole group those examples they are not sure about or that they do not agree on. As a whole group, the students will discuss the problematic examples and try to grasp the intended meaning behind them. If they are not able to do so themselves, the teacher will help the students. As for the second and third part of this teaching proposal, to be held in the middle of the course and a few days before it ends respectively, their structure will be quite similar. Both parts are to be held in just one or two one-hour sessions each. Once more, after a quick revision of the main concepts related to implicature, the students will be presented with further similar, although not exactly the same, scenarios as in the first part at the beginning of the course so as to interpret the intended meaning of those messages that contain implicature. To do so, they will be provided with both multiple choice and open-question questionnaires to be discussed first in pairs or in small groups, and then as a whole group.

Next, the students will be asked to produce in pairs or in small groups their own scenarios and messages in the FL containing implicature for their classmates to infer the implied meaning of the conversations. Finally, the students will share with their partners further examples of implicature that they have continued registering since the beginning of the course, first in pairs or in small groups, and then as a whole group. The purpose of these two last parts of the teaching proposal is to ascertain how much improvement may be perceived since the start of the course as far as pragmatic competence in the FL is concerned.

As happened with after the first part of the teaching proposal, there will be monthly sessions which serve as the basis for the discussion of further examples of implicature which the students have continued registering. At this moment, rather than raising awareness, these sessions are expected to lead to deeper and more critical reflection on this phenomenon. 


\section{Teaching proposal}

As specified in the previous section, this teaching proposal consists of three parts which include explicit instruction in implicature, especially the first one. In between, there will be monthly sessions for revision and consolidation, which will serve as the basis for the students' reflection on this phenomenon and which will help gauge whether they are grasping this concept. The first part of the proposal to be held at the beginning of the course aims to establish what the students know about implicature in general, and in English in particular. Apart from this, it will raise their awareness of the importance of this issue to communicate effectively in English and to avoid misinterpretations. This is the reason why it is the longest of the three. As it depends on how familiar the students are with this phenomenon, it is rather difficult to establish how long it will last, but it is estimated that at least three one-hour sessions will be required. This will depend on how much time is devoted to the explanations and the discussions that the students engage in, both in pairs or in small groups and as a whole group.

To begin the first part, the students will watch the first part of this video excerpt from YouTube: https://www.youtube.com/watch?v=4ED1tz4g0aE (0:22). This specific utterance by the doctor will be highlighted: "If there's anything wrong, I'll give you a call”. Immediately after that, the following excerpt containing the second part will be played: https://www.youtube.com/watch?v=xwHyIvjQiWk (0:30). Here, the main character is surrounded by his family and friends while he is talking to the doctor on the phone. The main character suddenly says “Are you serious?”, and a female character screams, "What is it?". The video will be paused at that moment and the students will be asked what they think that the doctor has told him.

The students will discuss it in pairs or in small groups for a few minutes, and then it will be done as a whole group. Once the discussion has finished, the rest of video will be seen, and they will be asked if they could imagine the doctor was phoning the main character to enquire about a real estate listing. As this is authentic language, which means it has not been adapted in any way to help FL learners understand it, if the students find it difficult to understand the excerpt, the utility of subtitles that comes with many YouTube videos will be enabled.

After seeing the end of the video, the students will be asked to discuss in pairs or in small groups whether something similar to this has ever happened to them in their mother tongue or in the FL. Besides, they will be encouraged to share with their 
partners whether they have ever misinterpreted a message in either language because they interpreted it literally rather than by paying attention to contextual factors or information. After a few minutes, the same question will be discussed as a whole group. Once this warm-up activity has finished, the students will be presented with the following video excerpts that include further examples of implicature:

- Video 1: https://www.youtube.com/watch?v=QOjsurQCZMk (2:10)

- Video 2: https://www.youtube.com/watch?v=7Bh62hP3n4M (0:57)

- Video 3: https://www.youtube.com/watch?v=opzS3idh4R8 (0:07)

As these videos will be used as focused-noticing activities, the students will be asked to discuss in pairs or in small groups what the problem seems to be in each case as regards the interpretation or misinterpretation of the messages seen in the videos. After a few minutes, this will be done as a whole group, in order to check whether they have come to similar conclusions as the ones provided here for each video:

- Video 1: Mrs. Beatty interprets that when a natural disaster occasionally strikes a country, it is almost certain that it will happen again at any time and, therefore, it is not a safe holiday destination. This is why she is happy with Finland, because as the travel agent tells her, "nothing bad ever happens in Finland". As a result, she sees it as a safe place because no natural disasters have been reported so far.

- Video 2:

a) Example 1. As the information on adoption is so detailed and "overwhelming" as the female character says, the male character prefers to focus on something more trivial like the fact of coming across a hair in his coffee, even though this decision is one of the most important ones to make in a person's lifetime.

b) Example 2. As there is only one muffin left, and the male character does want to have it and does not want the female character to eat it, he decides to lick the muffin and then offers it to her knowing that she will not want it then. In revenge, she decides to lick the rim of his cup of coffee and says, "Enjoy your coffee", meaning just the opposite as she cannot have the muffin she really wants to eat. 
c) Example 3. Even though it is raining heavily, and as a result both his raincoat and umbrella are really wet, the character says "Nice day we're having”, while meaning just the opposite.

- Video 3: The man on the right invites his colleague to go swimming to the beach with him. His colleague rejects the invitation saying "No way", because he has a lot of work to do. However, the man misinterprets it and he is not sure whether his colleague does not want to go with him because he dislikes either swimming or the beach. Consequently, he does not really know what the true reason is, i.e. that his colleague has so much work to do that he cannot go the beach with him.

These excerpts have been selected because, apart from being authentic, they are good examples of what implicature is and of how common it is to find it in different scenarios of our everyday lives, as those shown in the videos.

After these focused-noticing activities, the students will be provided with explicit instruction. Firstly, the teacher will introduce the concept of implicature in a very general way, and will refer to the examples that the students have already seen, so as to make it easier for them to understand this concept. After that, the following tutorials from YouTube will be played:

- Tutorial 1: Philosophy language conventional implicature: https://www.youtube.com/watch?v=YD821_bUhLc (7:16)

- Tutorial 2: Implicature: https://www.youtube.com/watch?v=yUs8GAi_cIw $(3: 53)$

These tutorials have been chosen as they are not extremely long, and because they provide the students with the theoretical background in a reasonably straightforward way. This makes them really appropriate so that the students can refer to them as many times as wished for revision and consolidation.

The first tutorial will be played on the first or second session, and the second video on the third one, i.e. the next day after the students attend class, which provides an opportunity to revise. As the tutorials include quite a lot of factual information that may be difficult for the students to process at once, the tutorial will be paused when the key 
ideas or concepts are introduced or mentioned so as to make sure that the students can grasp them. Thus, the instructor will also be able to clarify any queries they may have.

In order to make sure that the students have understood the key concepts, they will compare their mother tongue and the foreign language. Following Timple-Laughin's (2016) suggestion, explicit instruction will complement the comparison of specific pragmatic features or phenomena in both languages.

During the second session, the students will go through the multiple choice questionnaire (See appendix 2 for an example of a multiple choice questionnaire) in pairs or in small groups to establish how accurately they can interpret the messages in different scenarios. Then, the whole group will check the answers. If there is still some time left in the second session, or otherwise during the third one, the students will analyse further scenarios through an open-question questionnaire (See appendix 3 for an example of an open-question questionnaire). On this occasion the students will have no options to choose from. They will have to answer the question related to each situation. Once again, this will first be done in pairs or in small groups, and then the answers will be checked as a whole group.

Finally, working in pairs or in small groups, the students will be asked to think of their own scenarios and write a mini conversation to illustrate the concept of implicature, so as to present them to the rest of the group for their classmates to guess the implied meaning in each case. The students will have to think of at least one scenario and conversation that contains an implicature. This would be the equivalent of studentgenerated DCTs that McLean (2005) proposes.

To finish the first part of this teaching proposal, there will be a quick revision of the main concepts and ideas, and the students will be asked to start registering any examples of implicature that they come across from that moment onwards. For example, while watching TV programmes, films or videos in English, or reading novels or articles in English, or simply while having a conversation with a native English speaker. Apart from registering them, the students will be advised to analyse these examples or samples, in order to understand and interpret them accurately.

As already mentioned, before the mid-course session, there will be short monthly sessions for revision and consolidation. During them, apart from watching again some of the excerpts seen in the first part or new ones, the students will compare and discuss 
some of the examples of implicatures that they have been registering since the end of the first part. Little by little, these sessions will be used for critical reflection on this phenomenon and to determine whether they are grasping it.

As for the second and third parts of the teaching proposal, their structure will be quite similar. Each of them will be implemented in just one or two one-hour sessions in the middle of the course and a few weeks before its end respectively. Firstly, there will first be a quick revision of the key concepts concerning implicature. Then, the students will be presented with similar, although not exactly the same, scenarios as in the first part to interpret the intended messages that contain implicature.

To do so, they will be provided with both multiple choice and open-question questionnaires to be discussed first in pairs or in small groups, and then as a whole group. Next, the students will be asked to produce their own scenarios and mini conversations in the FL containing implicature in pairs or in small groups, so as to present them to the rest of the group for their classmates to guess the implied meaning in each case. The students will have to think of at least one scenario and conversation that trigger an implicature.

Finally, working in pairs or in small groups, the students will have to choose at least one example of implicature, and present it to their classmates, so that they try to guess its intended meaning. If the rest of the students cannot do so, they will have to explain it to their partners. Obviously, each pair or group of students will have to provide as much relevant information as possible as regards each scenario presented. As already mentioned, the purpose of these two final parts of the teaching proposal is to ascertain whether any improvement may be perceived throughout the academic year as far as the development of pragmatic competence in the FL is concerned. This is why there will be no explicit instruction in these two final parts unless it is necessary. As part of the third part of the proposal, the students will be asked to self- and peer assess how much they consider their grasp of implicature has improved since the beginning of the course. They will first do it individually, then they will discuss it in pairs or in small groups, and finally they will do so as a whole group. Apart from this self- and peer assessment, the teacher will provide individual feedback to each student, which will allow the students to compare to what extent their assessment coincides with their teacher's evaluation. Besides, the students will still be encouraged to continue registering and 
analysing any examples of implicature that they encounter throughout their lifelong learning process.

\section{Conclusions}

Most of the research studies carried out on the effects that explicit instruction has had in the experimental groups that have received it try to establish to what extent this instruction has helped to raise students' awareness of pragmatics in general, and of implicature in particular. This is also the case of this teaching proposal. After having implemented it, students are believed to be more likely to interpret those messages containing implicature more accurately, rather than just limiting themselves to interpreting their meaning literally.

Moreover, as some of the students with whom the teaching proposal is to be implemented are supposed to be already fairly autonomous learners, they are expected to have referred to the tutorials that have been selected to be used as the basis for the explicit instruction. Besides, it is believed that they will probably have searched for further tutorials on YouTube or reference material on this issue. As a result of this, and similarly to what Cignetti and Di Giuseppe (2015) point out, more marked differences among the students as regards pragmatic competence after explicit instruction are expected to be found. The reason for this will be that some of them will have a better understanding of implicature, and will also have developed their pragmatic competence to a higher extent than their partners.

With this teaching proposal, the short-term goal of making the students aware of the issue of implicature is expected to have been accomplished, especially during the first part. This is because it aims at raising their awareness of this issue and also to notice it, as O’Keeffe et al. (2011) highlight. The long-term goal that these authors also refer to of enabling students to be more pragmatically competent when it comes to implicature is also likely to be achieved, especially after the second and third parts of the teaching proposal.

Finally, as any practising teacher well knows, adjustments will surely have to be made to this teaching proposal as regards the estimated time for each main part, the materials to be used in class, the activities to be done, etc. This will depend on how well students understand the concept and how motivated they are by it. 


\section{References}

Alcón Soler, E. (2005). Does instruction work for learning pragmatics in the EFL context? System, 33(3), 417-435.

Bardovi-Harlig, K. (2001). Evaluating the empirical evidence: Grounds for instruction in pragmatics? In K. Rose \& G. Kasper (Eds.), Pragmatics in Language Teaching (pp. 13-32). Cambridge: Cambridge University Press.

Bardovi-Harlig, K., \& Mahan-Taylor, R. (2003). Introduction to teaching pragmatics. English Teaching Forum, 41(3), 37-39.

Bardovi-Harlig, K., Mossman, S., \& Su, Y. (2017). The effect of corpus-based instruction on pragmatic routines. Language Learning \& Technology, 21(3), 76-103.

Bardovi-Harlig, K., Mossman, S., \& Vellenga, H. E. (2015). Developing Corpus-Based M aterials to Teach Pragmatic Routines. TESOL Journal, 6(3), 499-526.

Blome-Ti llmann, M. (2013). Conversational implicatures (and how to spot them). Philosophy Compass, 8(2), 170-185.

Bouton, L. F. (1994). Can NNS skill in interpreting implicature in American English be improved through explicit instruction? -- A pilot study. Pragmatics and Language Learning, 5, 89-109.

Cignetti, L. M., \& Di Giuseppe, M. S. (2015). Pragmatic awareness of conversational implicatures and the usefulness of explicit instruction. Revista Nebrija de Lingüística Aplicada a la Enseñanza de Lenguas, 19.

Clennell, C. (1999). Promoting pragmatic awareness and spoken discourse skills with EAP classes. ELT Journal, 53, 83-91.

Cohen, A. D. (2010). Coming to terms with pragmatics. In N. Ishihara \& A. D. Cohen (2010), Teaching and learning pragmatics: Where language and culture meet (pp. 3-20). Harlow: Pearson Education.

Cohen, A. D. (2016). The teaching of pragmatics by native and nonnative language teachers: What they know and what they report doing. Studies in Second Language Learning and Teaching, 6(4), 561-585. 
Davis, W. A. (2016). Implicature. Oxford Handbooks Online. DOI: 10.1093/oxfordhb/9780199935314.013.21.

Eslami-Rasekh, Z. (2005). Raising the pragmatic awareness of language learners. ELT Journal, 59(3), 199-208.

Farashaiyan, A., Tan, K. H., \& Shahragard, R. (2018). An Evaluation of the Pragmatics in the "Cutting Edge" Intermediate Textbooks. 3L: The Southeast Asian Journal of English Language Studies, 24(4), 158-170.

Félix-Brasdefer, J. C. (2010). Data collection methods in speech act performance: DCTs, role plays, and verbal reports. In A. Martínez-Flor \& E. Usó-Juan (Eds.), Speech act performance: Theoretical, empirical and methodological issues (pp. 41-56). Amsterdam: John Benjamins.

Fukuya, Y. J., \& Martínez-Flor, A. (2008). The interactive effects of pragmatic-eliciting tasks and pragmatic instruction. Foreign Language Annals, 41(3), 478-500.

Ghasemi, A. A., \& Pasand, P. G. (2018). Pragmatic dimensions of Prospect Series: A textbook evaluation. Global Journal of Foreign Language Teaching, 8(3), 7686.

Goded Rambaud, M. (2012). Basic semantics. Madrid: Universidad Nacional de Educación a Distancia.

Grice, H. P. (1975). Logic and conversation. In P. Cole \& J. Morgan (Eds.), Syntax and Semantics, 3: Speech Acts (pp. 41-58). New York: Academic Press.

Hilliard, A. (2017). Twelve activities for teaching the pragmatics of complaining to L2 learners. English Teaching Forum, 55(1), 2-13.

Ishihara, N. (2010a). Lesson planning and teacher-led reflection. In N. Ishihara \& A. D. Cohen (2010), Teaching and learning pragmatics: Where language and culture meet (pp. 186-200). Harlow: Pearson Education.

Ishihara, N. (2010b). Class observation and teaching demonstrations. In N. Ishihara \& A. D. Cohen (2010), Teaching and learning pragmatics: Where language and culture meet (pp. 123-144). Harlow: Pearson Education. 
Ishihara, N., \& Cohen, A. D. (2010). Teaching and learning pragmatics: Where language and culture meet. Harlow, England: Pearson.

Jiang, N. (2000). Lexical representation and development in a second language. Applied Linguistics, 21(1), 47-77.

Judd, E. L. (1999). Some issues in the teaching of pragmatic competence. In E. Hinkel (Ed.), Culture in second language teaching and learning (pp. 152-166). Cambridge, England: Cambridge University Press.

Karlsson, A. (2019). Learning how to make requests in English: Pragmatic input in Swedish EFL textbooks. Available at: https://www.divaportal.org/smash/get/diva2:1290933/FULLTEXT01.pdf.

Kasper, G. (1999). Data collection in pragmatics research. University of Hawai'i Working Papers in ESL, 18(1), 71-107.

Kasper, G. (2001). Four perspectives on L2 pragmatic development. Applied Linguistics, 22(4), 502-530.

Kasper, G., \& Dahl, M. (1991). Research methods in interlanguage pragmatics. Studies in Second Language Acquisition, 13(2), 215-247.

Kecskes, I. (2014). Intercultural Pragmatics. New York: Oxford University Press.

Kecskes, I., \& Cuenca, I. M. (2005). Lexical choice as a reflection of conceptual fluency. International Journal of Bilingualism, 9(1), 49-67.

Kroll, J. F., \& Stewart, E. (1994). Category interference in translation and picture naming: Evidence for asymmetric connections between bilingual memory representations. Journal of Memory and Language, 33(2), 149-174.

Kubota, M. (1995). Teachability of conversational implicature to Japanese EFL learners. Institute for Research in Language Teaching Bulletin, 9, 35-67.

Leech, G. (1983). Principles of Pragmatics. London: Longman.

Levinson, S. C. (2000). Presumptive Meanings: The Theory of Generalized Conversational Implicature. Cambridge, MA: MIT Press.

Limberg, H. (2015). Principles for pragmatics teaching: Apologies in the EFL classroom. ELT Journal, 69(3), 275-285. 
Martínez-Flor, A., \& Beltrán-Palanques, V. (2013). Teaching refusal strategies in the foreign language classroom: a focus on inductive-deductive treatments. Journal of English Studies, 11, 41-67.

Martínez-Flor, A., \& Usó-Juan, E. (2010). Pragmatics and speech act performance. In A. Martínez-Flor \& E. Usó-Juan (Eds.), Speech Act Performance: Theoretical, Empirical and Methodological Issues (pp. 3-20). Amsterdam: John Benjamins.

Martínez-Flor, A., \& Usó-Juan, E. (2011). Research methodologies in pragmatics: Eliciting refusals to requests. ELIA, 11, 47-87.

McLean, T. (2005). “Why no tip?”: Student-generated DCTs in the ESL classroom. In D. Tatsuki (Ed.), Pragmatics in language learning, theory, and practice (pp. 150-156). Tokyo: Pragmatics Special Interest Group of the Japan Association for Language Teaching.

O’Keeffe, A., Clancy, B., \& Adolphs, S. (2011). Introducing pragmatics in use. London: Routledge.

Peccei, J. S. (1999). Pragmatics. London and New York: Routledge.

Rose, K., \& Kasper, G. (2001). Pragmatics in Language Teaching. Cambridge: Cambridge University Press.

Schmidt, R. (1990). The Role of Consciousness in Second Language Learning. Applied Linguistics, 11, 129-158.

Schmidt, R. (1995). Consciousness and foreign language learning: A tutorial on the role of attention and awareness in learning. In R. Schmidt (Ed.), Attention and awareness in foreign language learning (pp. 1-63). Honolulu: University of Hawai'i, Second Language Teaching \& Curriculum Center.

Sperber, D., \& Wilson, D. (2004). Relevance theory. In L. R. Horn and G. Ward (Eds.), Handbook of Pragmatics (pp. 607-632). Oxford: Blackwell.

Takahashi, S. (2001). The role of input enhancement in developing pragmatic competence. In K. Rose \& G. Kasper (Eds.), Pragmatics in Language Teaching (pp. 171-199). Cambridge: Cambridge University Press. 
Tateyama, Y. (2001). Explicit and implicit teaching of pragmatic routines. In K. Rose \& G. Kasper (Eds.), Pragmatics in Language Teaching (pp. 200-222). Cambridge: Cambridge University Press.

Thomas, J. (1983). Cross-cultural pragmatic failure. Applied Linguistics, 4(2), 91-112.

Timpe-Laughlin, V. (2016). Learning and development of second and foreign language pragmatics as a higher-order language skill: A brief overview of relevant theories (Research Report No. RR-16-35). Princeton, NJ: Educational Testing Service.

Tomlinson, B. (1994). Pragmatic awareness activities. Language Awareness, 3, 119129.

Tran, T. M. T., \& Yeh, A. (2020). Keeping it Real: Vietnamese-English Pragmatic Representations in EFL Textbook. International Journal of Language and Literary Studies, 2(1), 1-20.

Wang, K. (2019). Developing Communicative Competence: An Evaluative Study of Request and Apology in English Language Textbooks in China. Canadian Social Science, 15(8), 1-14.

Yoshimi, D. R. (2001). Explicit instruction and JFL learner's use of interactional discourse markers. In K. Rose \& G. Kasper (Eds.), Pragmatics in Language Teaching (pp. 223-247). Cambridge: Cambridge University Press. 
APPENDICES

Appendix 1. Overall structure of the teaching proposal

\begin{tabular}{|c|c|c|c|c|}
\hline \multicolumn{5}{|l|}{ Part 1} \\
\hline When & How long & Aim & Input & Activities \\
\hline $\begin{array}{l}\text { Beginning of } \\
\text { the course }\end{array}$ & $\begin{array}{l}\text { At least } 3 \\
\text { one-hour } \\
\text { sessions }\end{array}$ & $\begin{array}{ll}\text { - } & \text { Raising } \\
\text { - } & \text { awareness } \\
\text { - } & \text { Initial assessment } \\
\text { Creating } \\
\text { scenarios } \\
\text { containing } \\
\text { implicatures } \\
\text { - Starting to } \\
\text { register examples } \\
\text { of implicatures }\end{array}$ & $\begin{array}{ll}\text { - } & \text { Video excerpts } \\
\text { - } & \text { Tutorials }\end{array}$ & $\begin{array}{ll}\text { - } & \text { Warm-up activities } \\
\text { - } & \text { Focused-noticing } \\
\text { - } & \text { Extivities } \\
\text { Production } \\
\text { activities: multiple } \\
\text { choice and open- } \\
\text { question } \\
\text { questionnaires } \\
\text { Creating scenarios: } \\
\text { mini conversations }\end{array}$ \\
\hline \multicolumn{5}{|l|}{ In between } \\
\hline How often & How long & Aim & Input & Activities \\
\hline Once a month & $\begin{array}{l}1 \text { one-hour } \\
\text { session }\end{array}$ & 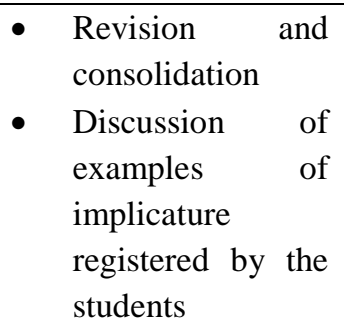 & $\begin{array}{ll}\text { - } & \text { Video excerpts } \\
\text { - } & \text { Examples } \\
\text { registered by } \\
\text { the students }\end{array}$ & 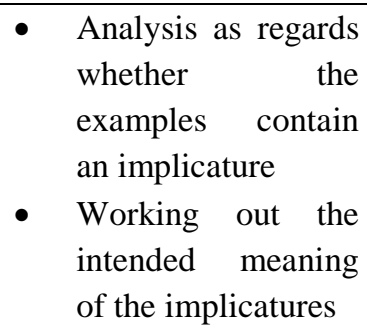 \\
\hline \multicolumn{5}{|l|}{ Part 2} \\
\hline When & How long & Aim & Input & Activities \\
\hline $\begin{array}{l}\text { Middle of the } \\
\text { course }\end{array}$ & $\begin{array}{l}1 \text { or } 2 \text { one- } \\
\text { hour } \\
\text { sessions }\end{array}$ & 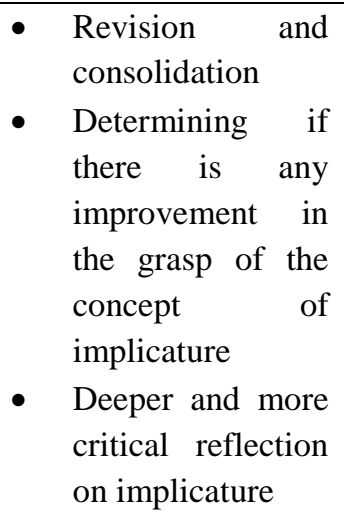 & $\begin{array}{ll}\text { - } & \text { Video excerpts } \\
\text { - } & \text { Questionnaires }\end{array}$ & $\begin{array}{ll}\text { - } & \text { Multiple choice } \\
\text { questionnaires } \\
\text { - } & \text { Open-question } \\
\text { questionnaires } \\
\text { - Creating scenarios } \\
\text { that contain } \\
\text { implicature }\end{array}$ \\
\hline \multicolumn{5}{|l|}{ In between } \\
\hline How often & How long & Aim & Input & Activities \\
\hline Once a month & $\begin{array}{l}1 \text { one-hour } \\
\text { session }\end{array}$ & $\begin{array}{ll}\text { - } & \begin{array}{l}\text { Revision and } \\
\text { consolidation }\end{array} \\
\text { - } & \begin{array}{l}\text { Discussion } \\
\text { examples of }\end{array} \\
\text { implicature } & \\
& \text { registered by } \\
\text { students } & \end{array}$ & $\begin{array}{ll}\text { - } & \text { Video excerpts } \\
\text { - } & \text { Examples } \\
\text { registered by } \\
\text { the students }\end{array}$ & 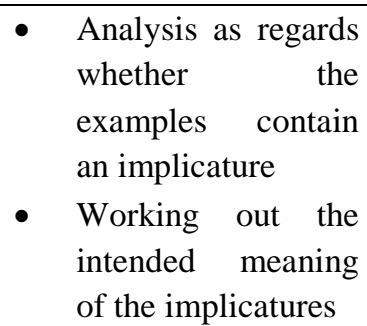 \\
\hline \multicolumn{5}{|l|}{ Part 3} \\
\hline When & How long & Aim & Input & Activities \\
\hline
\end{tabular}




\begin{tabular}{|c|c|c|c|c|}
\hline $\begin{array}{l}\text { End of the } \\
\text { course }\end{array}$ & $\begin{array}{l}1 \text { or } 2 \text { one- } \\
\text { hour } \\
\text { sessions }\end{array}$ & 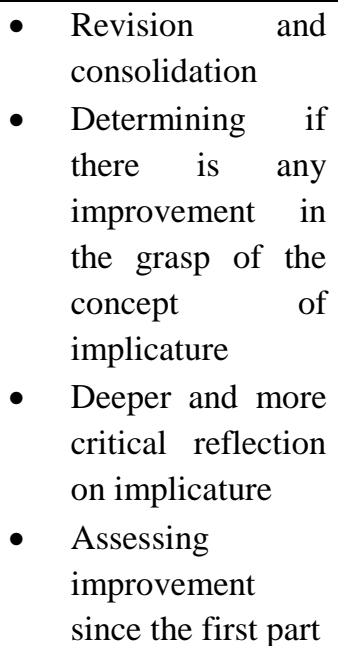 & $\begin{array}{ll}\text { - } & \text { Video excerpts } \\
\text { - } & \text { Questionnaires }\end{array}$ & 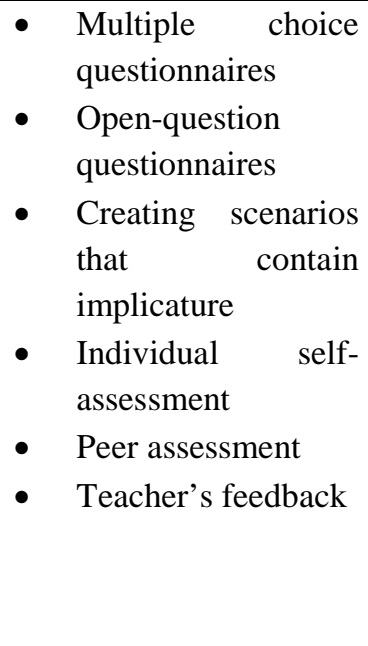 \\
\hline
\end{tabular}


Appendix 2. An example of a multiple choice questionnaire (Slightly adapted from Cignetti \& Di Giuseppe, 2015, pp. 13-16)

Please read the following situations and choose the correct response to the question underneath each scenario.

\section{Situation 1:}

Bill and Peter have been colleagues for many years. Now Bill and one of his closest friends, also working for the same company, are talking about what happened at work yesterday after he left the office.

Bill's friend: Bill, I'm sorry to say this, but I heard Peter telling our boss that you were late for work last Tuesday.

Bill: $\quad$ Peter knows how to be a good friend.

Which of the following interpretations best expresses what Bill means?
a) Peter is not acting the way a friend should.
b) Peter and Bill's boss are becoming really good friends.
c) Peter is a good friend, so Bill can trust him.
d) Nothing should be allowed to interfere with Bill and Peter's friendship.

\section{Situation 2:}

One morning Frank and Helen were talking outside their house. Frank wanted to know what time it was, but he didn't have a watch.

Frank: What time is it, Helen?

Helen: The postman has already been here.

Frank: OK. Thanks.

What does Frank probably understand from what Helen says?

a) She is telling him approximately what time it is by saying that the postman has already been here. 
b) By changing the subject, Helen is telling Frank that she does not know what time it is.

c) She thinks that Frank should stop what he is doing and read his mail.

d) Frank will not be able to derive any message from what Helen says, since she did not answer his question.

\section{Situation 3:}

Three close friends have to submit a paper this week. Yesterday, Chris wrote the first part of the paper and sent it to Laura and Mike.

Laura: Have you finished reading what Chris wrote yet?

Mike: Yeah, I read it last night.

Laura: What did you think of it?

Mike: I thought it was well-typed.

Did Mike like Chris’s paper?

a) He liked it and thought it was good.

b) He thought it was important that the paper was well typed.

c) He really hadn't read it well enough to know.

d) He didn't like it.

\section{Situation 4:}

A group of students are talking about their coming holiday. They would like to leave a day or two earlier, but one of their professors has said that they will have a test on the day before holiday begins. None will be excused, he said. Everyone had to take it. After class, some of the students get together and talk about the situation, and their conversation goes as follows:

Kate: I wish we didn't have that test next Friday. I wanted to leave to Florida before that. 
Jake: Oh, I don't think we'll really have that test. Do you?

Mark: Professor Schmidt said he wasn't going anywhere this holiday. What do you think, Kate? Will he really give us that test?

Kate: Does the sun come up in the east these days?

What is the point of Kate's question?

a) I don't know. Ask me a question I can answer.

b) Let's change the subject before we get really angry about it.

c) Yes, he'll give us the test. You can count on it.

d) Almost everyone else will be leaving early. It always happens. We might as well do it, too.

\section{Situation 5:}

Lars: Where's Rudy, Tom? Have you seen him this morning?

Tom: There’s a yellow Honda parked over by Sarah’s house.

What Tom is saying is that...

a) He just noticed that Sarah has bought a new yellow Honda.

b) He doesn't know where Rudy is.

c) He thinks Rudy may be at Sarah's house.

d) He likes yellow Hondas and wants Lars to see one.

The correct answer for each situation comes in bold. 
Appendix 3. An example of an open-question questionnaire (Slightly adapted from https://thedefinitearticle.aqa.org.uk/2016/11/17/understanding-implicatures-classroomactivity/)

Please read the following situations and answer the question underneath each one.

Situation 1:

Andy: Are you going to read Scott's new book when it's out?

Bella: I read everything he writes.

Is Bella going to read the book?

(Yes, she is)

Situation 2:

Andy is asking Bella about an essay which she has been trying to write for a long time.

Andy: How’s the essay going?

Bella: Lovely weather just now, isn't it?

Has Bella finished it or written most of it?

(No, she hasn't. She might not have even started it or written anything since the last time they talked about it)

\section{Situation 3:}

Andy is asking Bella about her new employee Neil.

Andy: How's Neil getting on? Is he a good worker?

Bella: Well, he always arrives in good time. 
Does Bella think Neil is a good employee?

(She does not seem to believe so, but she wants to say something positive about him).

\section{Situation 4:}

Andy: Do you know if Scott's going to Ellen's party?

Bella: Jake’s going.

Do you think Scott is going to the party?

(If he likes Jake, he will probably be going. Otherwise, he is unlikely to go).

\section{Situation 5:}

Andy: Would you like a coffee?

Bella: Coffee would keep me awake.

Is Bella going to have a coffee?

(She is unlikely to have it, because if she does, then she will not be sleeping at night).

The suggested answers for each situation come in brackets. 